\title{
Improving the presentation of safety briefings using the graphical method on the example of fire safety
}

\author{
Mariya Ryzhikova ${ }^{1}$, Evgeniya Fedotova ${ }^{1}$, and Fedor Gomazov ${ }^{1, *}$ \\ ${ }^{1}$ Peter the Great St. Petersburg Polytechnic University, Polytechnicheskaya, 29, St.Petersburg, 195251, Russia
}

\begin{abstract}
Ensuring fire safety is an important function of the state, which includes a set of measures to ensure the prevention of fires, their direct suppression and the conduct of rescue operations at the site.This article deals with the problems of providing instructions on fire safety. Based on the synthesis of the functions of the fire safety system, the tasks of the fire department and the statistical data of appeals to the fire service, as well as the provisions of the Federal Law of the Russian Federation, an idea was put forward to solve these problems. On the basis of the organization and implementation of fire prevention, which included conducting briefings and special classes with workers and employees of the fire safety facility, as well as other persons potentially associated with the occurrence of a fire, an operation was conducted to simulate a graphical presentation of fire safety briefings. Using the methodology of V.G. Burlov, the effectiveness of the use of improved fire safety instruction was proved.
\end{abstract}

\section{Introduction}

Fire safety is a state of protection of a person, property, society as a whole and the state from the probability of occurrence and development of fires. [1]

The state should ensure the fire safety of people regardless of their occupation [2]: during labor and training activities. [3]

According to statistical data of the Ministry of Emergency Situations of Russia, Federal State Budgetary Institution "All-Russian Research Institute for Civil Defense and Emergencies" for 2017, organizations registered 581 fires. [4] Fires cause enormous damage to the population and the state. The results of fires are large economic losses, and in some cases, human casualties. That is why the provision of fire safety is the most important task of each member of society and is carried out on a nationwide scale. This article discusses the improvement and the need for briefings on fire safety at production facilities.

Consider the main tasks of the fire department. These are:

- Organization and implementation of fire prevention. [5-7]

- Rescue of people and property in case of fires, first aid.

- Organization and implementation of extinguishing fires and conducting rescue operations. [8]

Fire safety training is conducted according to the fire briefing program [9] and / or the fire-technical minimum with persons engaged in labor or official activities in various organizations. [10]
The analysis of the effectiveness of the improved instruction was carried out according to the methodology of V.G. Burlov. [11]

To assess the effectiveness of the developed instruction, a test of 5 questions was compiled. Previously, students of the 3rd year at the Higher School of Engineering and Technology at St. Petersburg University were divided into 2 groups. The first group studied advanced graphic instruction for 15 minutes. The second group got acquainted with the points from the Federal Law also for a limited period of 15 minutes. In both cases the points were presented:

1)Ensuring that the manager complies with the marking requirements when working with fire-hazardous substances.

2)The ban on the joint use, storage and transportation of fire-hazardous substances.

3)Providing the supervisor with work on cleaning the premises from industrial waste.

4)Impregnation of workers' working clothes with flame retardant.

Installation of the nearest exit signs not less than 60 $\mathrm{m}$ in cable structures [12].

\section{Results}

In the first stage of the experiment, the two groups of students had a fixed time to familiarize themselves with the material. It was $15 \mathrm{~min}$ (more $t 1=t 2=15 \mathrm{~min}$ ).

The next stage of the experiment was a test of the material studied.

In the experiment a group of students who studied advanced coaching, decided to take the test for 3 min 10

\footnotetext{
* Corresponding author: gomazov_fa@spbstu.ru
} 
sec (more $\left.t 1^{\prime}\right)$. Time for a test of the second group studied the text instruction, was 5 min $50 \mathrm{sec}$ (more $t 2$ ').

Based on the methodology V. G Burlow [9] was set to the following variables:

- the intensity of familiarization with the material;

$$
v_{1}=\frac{1}{t 1}=\frac{1}{t 2}
$$

- the intensity of the test solution.

$$
v_{2}=\frac{1}{t 1^{\prime}} \text { and } \frac{1}{t 2^{\prime}}
$$

The fire intensity per year:

$$
\begin{gathered}
\lambda=\frac{581}{1} \\
\lambda=\frac{581}{365 * 24 * 60 * 60}, s
\end{gathered}
$$

The test success rate for the first group of subjects:

$$
P_{1}=\frac{\frac{1}{900} * \frac{1}{190}}{\frac{581}{365 * 24 * 60 * 60}\left(\frac{581}{365 * 24 * 60 * 60}+\frac{1}{900}+\frac{1}{190}\right)+\frac{1}{900} * \frac{1}{190}}=0,98026
$$

The test success rate for the second group of subjects:

$$
P_{2}=\frac{\frac{1}{900} * \frac{1}{350}}{\frac{581}{365 * 24 * 60 * 60}\left(\frac{581}{365 * 24 * 60 * 60}+\frac{1}{900}+\frac{1}{350}\right)+\frac{1}{900} * \frac{1}{350}}=0,97739
$$

To determine the effectiveness of the use of advanced instruction, it is necessary to evaluate the success of passing the test by instructing an experimental group.

\section{Conclusion}

As a result of the study, it was found that the results of the success rate of passing the test of the first and second test groups diverge. Despite the fact that the time for acquaintance with the points of the Federal Law was given the same, the group studying the points of the Federal Law with a graphical representation had a result of $98 \%$ of the test passing success, and the group that studied the points directly reading the law received a result of $97.7 \%$

Based on the data obtained, it can be concluded that

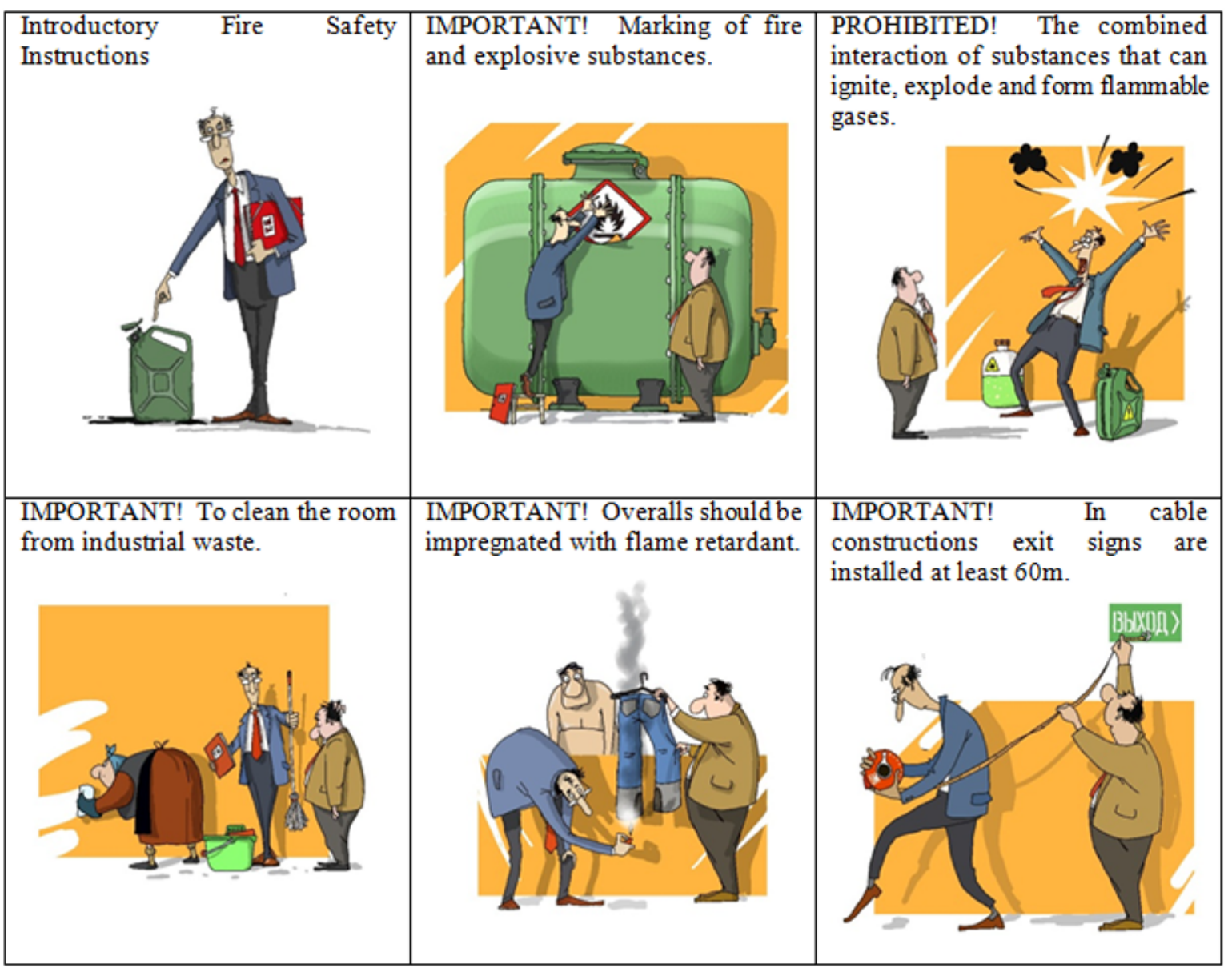

Fig. 1. Example. 
the proposed format of fire safety briefings at production facilities allows reducing time and improving the efficiency of material perception by trainees, while this practice can be extended to all areas of activity and all types of briefings. Further work will be to create typical briefings using the graphical method.

\section{References}

1. The Law of the Russian Federation "On Fire Safety" dated 21.12.1994 No. 69 // Collection of the legislation of the Russian Federation. Art. 1. rev. and add. in ed. dated 10.30.2018

2. O.D. Ratnikova, Fire prevention: a textbook for students in educational institutions of higher education EMERCOM of Russia M .: VNIIPO, 414 (2017)

3. W.F.W. Ahmad, A. Sarlan, N.A. Rauf, ESCAPE: Interactive fire simulation and training for children using virtual reality doi:10.1007/978-3-319-990071_62 (2019)

4. State report "On the state of protection of the population and territories of the Russian Federation from natural and man-made emergencies in 2017" / Moscow: EMERCOM of Russia. FSBI ARRI CDE, 376 (2018)

5. R. I. Moraru, M. Sroka, Improved education and trainings in the field of fire protection. Paper presented at the MATEC Web of Conferences, 183 doi:10.1051/matecconf/201818304011 (2018)

6. A. Ustinov, O. Zybina, A. Tomakhova, S. Pavlov, The enhancement of operating properties of intumescent fire-protective compositions MATEC Web of Conferences 24511008 (2018)

7. Idrisova, J.I., Myasnikov, V.N., Uljanov, A.I., Belina, N.V. Increasing the efficiency of labor protection in the enterprise International Conference on Information Networking, 2018-January, 586-588 (2018)

8. The Law of the Russian Federation "On Fire Safety" dated 21.12.1994 No. 69 // Collected Legislation of the Russian Federation. Art. 4. rev. and add. in ed. dated 10.30.2018

9. Order of the Ministry of Emergency Situations of the Russian Federation "On Approval of the Fire Safety Standards" Training of Fire Safety Measures for Employees of Organizations "dated 12.12.2007 No. 645 // Meeting of the Legislation of the Russian Federation. Article II. Fire Safety Briefing

10. Law of the Russian Federation "On Fire Safety" dated 21.12.1994 No. 69 Collected legislation of the Russian Federation. Art. 25. as amended and add. in ed. dated 10.30.2018

11. V.G. Burlov, F.A. Gomazov, A.V. Andreev, Technology of management of processes of ensuring safety of labor activities // xxi century: results of the past and problems of the present plus. Penza: Penza State Technological University (2018)
12. Decree of the Government of the Russian Federation "On Fire Fighting Regime" dated 25.04.2012 No. 390 // Collected Legislation of the Russian Federation. Art. 9 